Original Research Article

\title{
Prescription pattern of drugs in ENT outpatient department of tertiary care teaching hospital
}

\author{
Usha Joshi $^{1 *}$, Hansa Banjara ${ }^{2}$, Rajesh Hishikar ${ }^{1}$, Ravindra Chandrakar ${ }^{1}$
}

\begin{abstract}
${ }^{1}$ Department of Pharmacology,
${ }^{2}$ Department of ENT, Pt. J.N.M.

Medical College, Raipur,

Chhattisgarh, India
\end{abstract}

Received: 23 July 2018

Accepted: 07 August 2018

*Correspondence to:

Dr. Usha Joshi,

Email: ushajoshi2012@

gmail.com

Copyright: (C) the author(s), publisher and licensee Medip Academy. This is an openaccess article distributed under the terms of the Creative Commons Attribution NonCommercial License, which permits unrestricted noncommercial use, distribution, and reproduction in any medium, provided the original work is properly cited.

\begin{abstract}
Background: Diseases of the ear, nose and throat (ENT) are common among general population affecting all age groups and accounts for most of the drugs prescribed and used. The aim of the study is to assess the prescription pattern of drugs in ENT outpatient department in a tertiary care teaching hospital.

Methods: A prospective observational study was conducted from December 2017 to May 2018 in the ENT OPD (Outpatient department) at Pt. J.N.M. Medical College and associated Dr. B.R. Ambedkar Memorial Hospital, Raipur. Data were collected in a proforma and evaluated.

Results: A total of 313 prescriptions were analysed. Most of the patients (40.89\%) belonged to 13 - 35 years age group.185 patients $(59.10 \%)$ were male and 128 patients were females $(40.90 \%)$. A total of 1003 drugs were prescribed. The average number of drugs per prescription was 3.2. Most common class of drugs prescribed was antimicrobials $(24.42 \%)$, followed by $\mathrm{H} 1$ antihistaminics (18.84\%), antiulcer drugs $(15.55 \%)$ and nonsteroidal anti-inflammatory (NSAIDs) drugs (14.35\%). The average number of antimicrobials per prescription was 0.78 . One or two antimicrobials were prescribed in 202 prescriptions $(64.53 \%)$. The most common prescribed antimicrobial was of Penicillin group $(64.89 \%)$ followed by Fluoroquinolone $(25.71 \%)$. The most common prescribed route of drug administration was oral route $(81.35 \%)$. The most common prescribed dosage form was tablets $(74.87 \%)$. FDC constituted $24.62 \%$ of prescribed drugs.

Conclusions: The study revealed that the most common class of drug prescribed was antimicrobials followed by $\mathrm{H} 1$ antihistaminics, antiulcer drugs and NSAIDS.
\end{abstract}

Keywords: Antimicrobials, ENT, Outpatient department, Prescription pattern

\section{INTRODUCTION}

Study of prescription pattern is important to assess the pattern of drug used. The World Health Organization (WHO) defined drug utilization as "the marketing, distribution, prescription and use of drug in a society with special emphasis on the resulting medical, social and economic consequence." 1

Drug utilization research help to estimate number of patients exposed to specified drugs within a given time period, determine the pattern of drug use. ${ }^{2}$
The study of drug utilization helps in identifying the problems associated with drug usage in healthcare system as well as remarks the current approaches to the rational use of drugs. ${ }^{3}$

WHO defines rational use of medicines as "patients receive medications appropriate to their clinical needs, in doses that meet their own individual requirements, for an adequate period of time and at the lowest cost to them and their community. ${ }^{4}$

Diseases of ENT commonly affect the general population. These diseases may vary from common cold to 
complicated chronic suppurative otitis media (CSOM). ENT diseases affect all the age group ranging from children to adults with significant disability-adjusted life (DALY) of patients. ${ }^{5}$ Various ENT diseases like upper respiratory tract infections, acute suppurative otitis media, chronic suppurative media are common.

According to WHO report respiratory tract infections were the fourth major cause of mortality constituting $7.4 \%$ in females and $7.1 \%$ in males. ${ }^{6}$

Various drugs including antimicrobials are used for the treatment of ENT diseases though inappropriate use of the antimicrobials is a major problem as it can lead to development of drug resistance. Thus, it becomes necessary to monitor and evaluate different drug use patterns in the course of time and make necessary modification in the pattern of prescription so as to increase its therapeutic benefit and decrease its adverse effects. ${ }^{7}$

Thus the present study is intended to assess the prescription pattern of drugs in ENT OPD in this institute. This would encourage good evidence based practice and facilitate appropriateness of drug use.

\section{METHODS}

The study was conducted in the ENT OPD and Department of Pharmacology, in Pt. J.N.M. Medical College and associated Dr. B.R. Ambedkar Memorial Hospital, Raipur, Chhattisgarh. The study was approved by the Institutional Ethics Committee.

This is a prospective observational study to evaluate the prescription pattern of drugs in ENT OPD. The study was carried out from December 2017 to May 2018 (six months). The study population consists of 313 patients who qualified for the inclusion criteria. Patients of either sex, visiting ENT OPD and giving consent were included in the study.

\section{Data collection}

A total of 313 prescriptions were analysed at varying time interval from the ENT OPD during a six months period. Data regarding demographics such as age, sex, WHO prescribing indicators which includes the average number of drugs prescribed per prescription, percentage of antimicrobials prescribed, percentage of other drugs prescribed, percentage of drugs prescribed by different routes, its dosage form, frequency, duration of treatment and FDC were collected in a predesigned proforma. ${ }^{8}$ The collected data was analyzed and results were expressed as mean, number and percentage.

\section{RESULTS}

A total of 313 prescriptions were analysed in this study. Majority of the patients were between the age group of 1335 years age group (40.89\%), followed by $>35$ years age group (33.54\%), 6-12 years age group (14.69\%) and least were in the age group of $0-5$ years age group (10.86\%) (Table 1).

Table 1: Age distribution of patients in this study $(n=313)$.

\begin{tabular}{|lll|}
\hline Age (in years) & $\begin{array}{l}\text { Number of } \\
\text { patients }\end{array}$ & $\begin{array}{l}\text { Percentage } \\
(\%)\end{array}$ \\
\hline $0-5$ & 34 & 10.86 \\
\hline $6-12$ & 46 & 14.69 \\
\hline $13-35$ & 128 & 40.89 \\
\hline$>35$ & 105 & 33.54 \\
\hline
\end{tabular}

In this study the male patients were $185(59.10 \%)$ and female patients were $128(40.90 \%)$ (Table 2).

\section{Table 2: Sex distribution of patients in this} study $(n=313)$.

\begin{tabular}{|lll|}
\hline Gender & Number of patients & Percentage (\%) \\
\hline Male & 185 & 59.10 \\
\hline Female & 128 & 40.90 \\
\hline
\end{tabular}

The total number of drugs prescribed was 1003.The average number of drugs per prescription was 3.2. The total number of antimicrobials prescribed was 245 . The average number of antimicrobials per prescription was 0.78 (Table 3).

Table 3: Prescription parameter.

\begin{tabular}{|ll|}
\hline Parameters & Numbers \\
\hline Total number of prescriptions analysed & 313 \\
\hline Total number of drugs prescribed & 1003 \\
\hline Average number of drugs per prescription & 3.2 \\
\hline $\begin{array}{l}\text { Total number of prescriptions containing } \\
\text { antimicrobials }\end{array}$ & 202 \\
\hline Total number of antimicrobials prescribed & 245 \\
\hline $\begin{array}{l}\text { Average number of antimicrobials per } \\
\text { prescription }\end{array}$ & 0.78 \\
\hline Total number of FDC prescribed & 247 \\
\hline
\end{tabular}

Table 4: Number of drugs prescribed per prescription.

\begin{tabular}{|ll|}
\hline $\begin{array}{l}\text { Number of drugs per } \\
\text { prescription }\end{array}$ & Number of prescriptions \\
\hline 1 drug & 28 \\
\hline 2 drugs & 65 \\
\hline 3 drugs & 88 \\
\hline 4 drugs & 85 \\
\hline 5 drugs & 41 \\
\hline 6 drugs & 06 \\
\hline
\end{tabular}

In this study, 88 patients were prescribed 3 drugs (28.11\%), 85 patients with 4 drugs $(27.15 \%)$ followed by 65 patients prescribed with 2 drugs $(20.76 \%)$ (Table 4$)$. 
The most frequent prescribed class of drug was antimicrobials (24.42\%), $\mathrm{H}_{1}$ antihistaminics (18.84\%), anti ulcer drugs $(15.55 \%)$ followed by NSAIDs (14.35\%) (Figure 1).

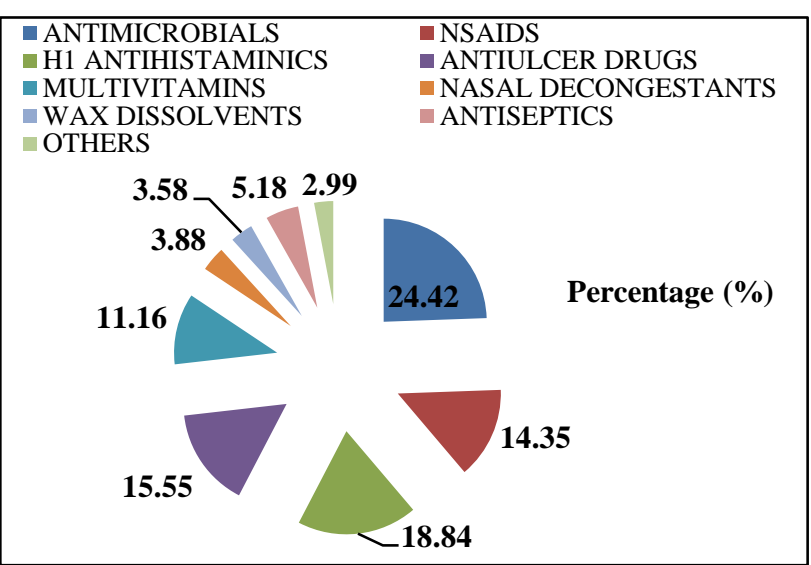

Figure 1: Percentage distribution of class of drugs prescribed including combinations.

In 202 prescriptions antimicrobials were prescribed, out of which 159 prescriptions had one antimicrobial prescribed in each whereas 43 prescriptions had 2 antimicrobials prescribed in each (Table 5).

Table 5: Number of antimicrobials per prescription.

\begin{tabular}{|lll|}
\hline $\begin{array}{l}\text { Number of } \\
\text { antimicrobials per } \\
\text { prescription }\end{array}$ & $\begin{array}{l}\text { Number of } \\
\text { prescriptions }\end{array}$ & $\begin{array}{l}\text { Percentage } \\
(\%)\end{array}$ \\
\hline One & 159 & 50.8 \\
\hline Two & 43 & 13.7 \\
\hline No antimicrobials & 111 & 35.5 \\
\hline Total & 313 & 100 \\
\hline
\end{tabular}

The most common prescribed class of antimicrobials and its various combinations was Penicillins (64.89\%), Fluoroquinolones $(25.71 \%)$ followed by Chloramphenicol $(3.67 \%)$ (Figure 2).

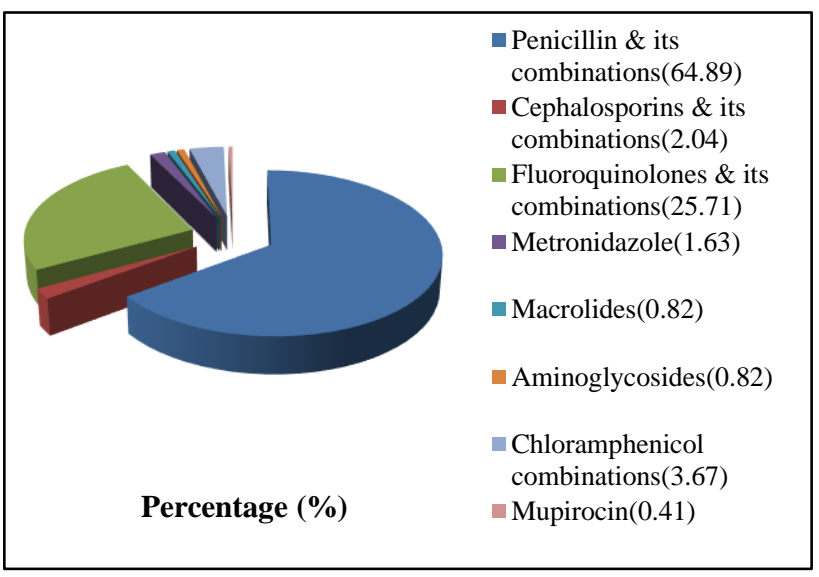

Figure 2: Percentage distribution of class of antimicrobials prescribed.
The most common antimicrobial prescribed was the combination of Amoxicillin-Clavulanic acid (62.04\%) (Figure 3).

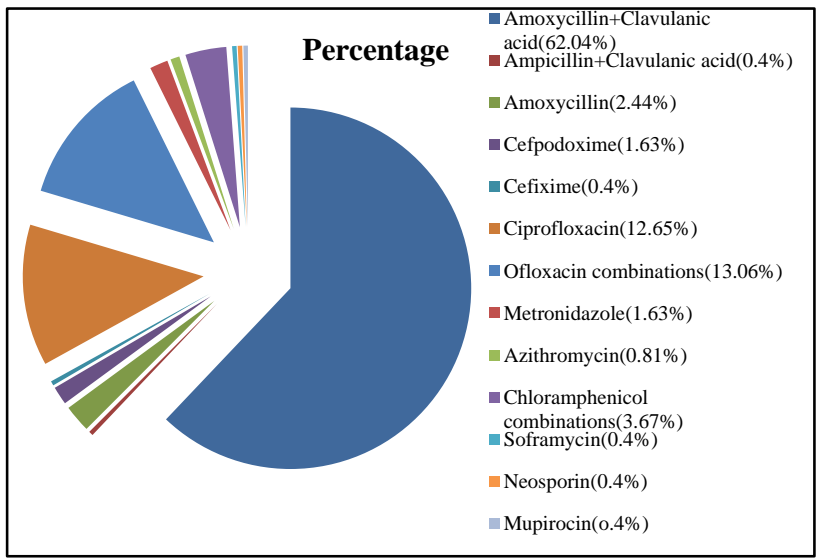

Figure 3: Percentage distribution of antimicrobials prescribed.

A total of $189 \mathrm{H}_{1}$ antihistaminics were prescribed alone or in combinations out of which Levocetrizine was the most commonly prescribed $\mathrm{H}_{1}$ antihistaminics (68.25\%) (Figure 4).

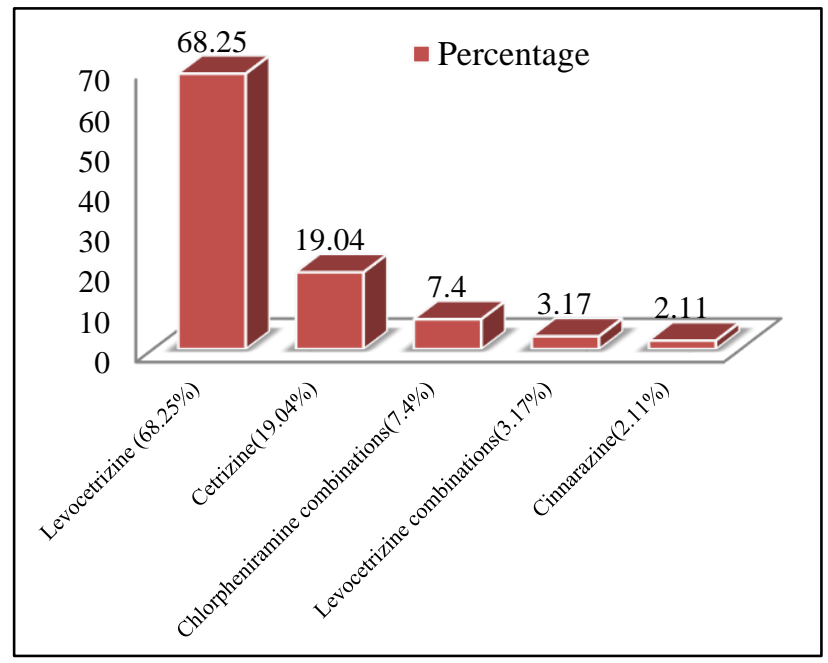

Figure 4: Percentage distribution of $\mathrm{H1}$ antihistaminics prescribed.

A total of 144 NSAIDS was prescribed either alone or in combinations out of which Paracetamol was the commonest prescribed NSAIDS (67.36\%) (Figure 5).

This study also revealed that the most common route of drug administration prescribed was oral route in 816 drugs $(81.35 \%)$ followed by topical route in 186 drugs $(18.54 \%)$ (Figure 6).

The most common dosage form prescribed was Tablets (751; 74.87\%), followed by Drops $(134 ; 13.35 \%)$, Syrups $(54 ; 5.38 \%)$ (Figure 7). 


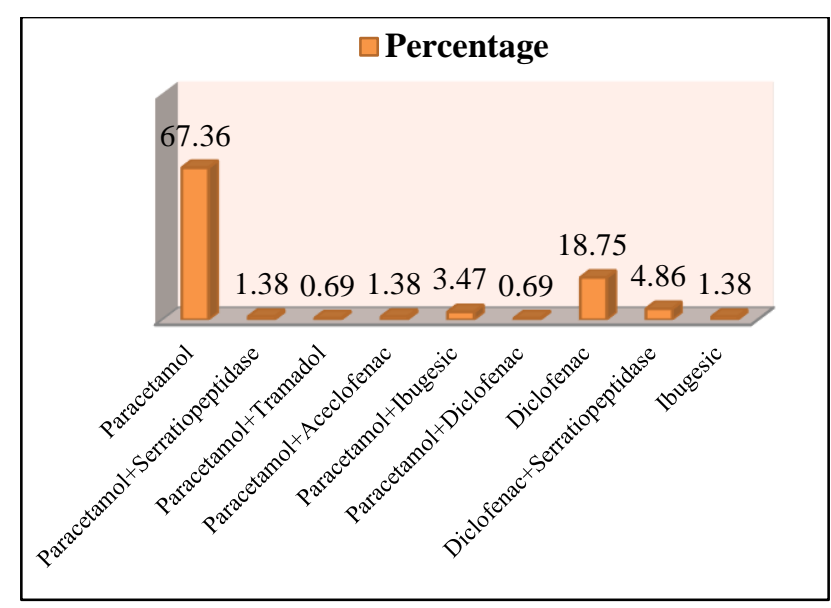

Figure 5: Percentage distribution of NSAIDS prescribed.

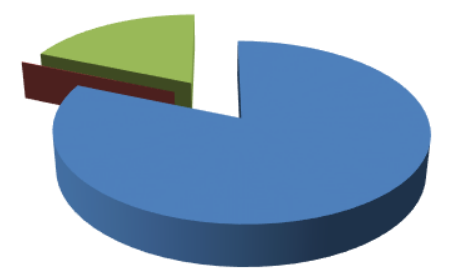

$$
\begin{aligned}
& \text { Oral }(81.35 \%) \\
& \text { Topical }(18.54 \%)
\end{aligned}
$$

Figure 6: Percentage distribution of routes of
drug administration.

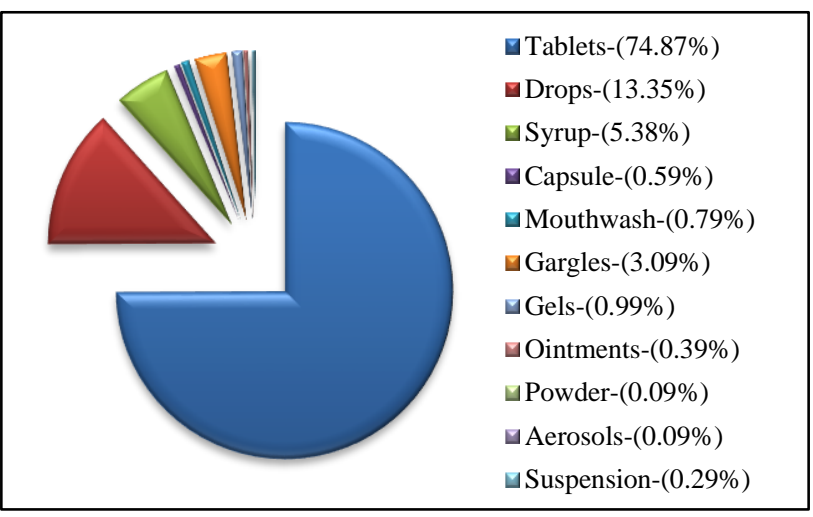

Figure 7: Percentage distribution of dosage form prescribed.

A total of 247 fixed dose combinations were prescribed out of which Amoxicillin-Clavulanic acid combination was the most common $(152 ; 61.53 \%)$ prescribed FDC. This study also revealed that the chief complaints were mentioned in 250 prescriptions (79.87\%), whereas diagnosis was mentioned in 75 prescriptions (23.96\%). Out of 1003 drugs, duration of treatment was not mentioned in 36 drugs $(3.5 \%)$ and frequency of drug administration was not mentioned in 26 drugs (2.59\%).

\section{DISCUSSION}

Prescription pattern studies are necessary to obtain data on drug use. In this study the maximum patients belonged to the age group of $13-35$ years $(40.89 \%)$. Male patients were predominant $(59.10 \%)$. This is in accordance with the studies of Pradhan S et al, and Sridevi SA et al. ${ }^{9,10}$

This study reveals that 3.2 drugs were prescribed per prescription. 88 patients $(28.11 \%)$ had received 3 drugs per prescription followed by 85 patients $(27.15 \%)$ who were prescribed 4 drugs per prescription. A study by Padwal et al showed that the average number of drugs per prescription was 3.9. ${ }^{11}$ A similar hospital based study revealed that the average number of drugs prescribed per prescription was $3 .{ }^{12}$ However it has been advised that the average number of drugs prescribed per prescription should be kept to minimum in order to prevent antibiotic resistance, drug to drug interactions and adverse drug reactions. ${ }^{13,14}$

The study also revealed that amongst the different class of drugs, most common prescribed class of drugs were antimicrobials $(24.42 \%)$ followed by $\mathrm{H}_{1}$ antihistaminics (18.84\%), anti-ulcer drugs (15.55\%), NSAIDS (14.35\%) and multivitamins $(11.26 \%)$. A study by Padwal et al, revealed in their study that the most common drug prescribed was antimicrobials $(24.86 \%)$ followed by NSAIDS (23.6\%), gastroprotective (22.55\%) and antihistaminics $(19.92 \%){ }^{11}$

In this study the most common class of antimicrobial prescribed was penicillin $(64.89 \%)$ followed by fluoroquinolones $(25.71 \%)$. A study conducted by Bhat GMN et al, study by Sumalatha R et al, and other studies, have revealed that $B$ Lactum (penicillins and cepahalosporins) were the most commonly prescribed antimicrobials. ${ }^{12,15-17}$ The most common antimicrobial prescribed in this study was amoxicillin-clavulanic acid $(62.04 \%)$. This finding was in accordance with the study of Bhat GMN et al, and Suman RK et al. ${ }^{12,18}$

Regarding other class of drugs prescribed, our study revealed that amongst NSAIDS, paracetamol was the most common prescribed drug $(67.36 \%)$ which is a good indicator as it is associated with least side effects. Similarly, amongst $\mathrm{H} 1$ antihistaminics, levocetrizine was the most common prescribed $\mathrm{H}_{1}$ antihistaminic (68.25\%) which is from the second generation non- sedating antihistaminics. These groups of drugs were prescribed for the symptomatic treatment. Multivitamins were prescribed for oral ulcers and to patients on antibiotics. Anti-ulcer drugs were prescribed to combat drug induced gastritis.

Majority of drugs were prescribed by oral route $(81.35 \%)$ followed by Topical route $(18.54 \%)$. None of the prescribed drugs were administered via injections. This may be as this study is done on OPD patients. This is a welcome step and has to be encouraged. Similar findings were seen in the study done by Padwal et al, and Sumalatha 
R et al. ${ }^{11,15}$ The most common dosage form prescribed was Tablet followed by drops and syrups.

The age, sex, dosage forms were written in all prescriptions. The routes of administration and frequency of doses were appropriate in the majority of cases. In writing prescription, it is found that chief complaints were mentioned in $79.87 \%$ prescriptions whereas diagnosis was mentioned in $23.96 \%$ prescriptions. As most of the collected prescriptions were prescribed by the resident doctors in the outpatient department, probably diagnosis was made by the consultant after discussion/ investigation report or histopathological report.

The study was conducted for a period of six months; hence seasonal variation in the pattern of disease may be different which may affect the prescribing patterns of drug.

\section{CONCLUSION}

The study showed the most common class of drug prescribed were antimicrobials followed by $\mathrm{H}_{1}$ antihistaminics, anti-ulcer drugs and NSAIDs. The most common antimicrobial prescribed was the amoxicillinclavulanic acid combination. Most common route of administration prescribed was oral and the most common dosage form prescribed was tablets. Prescription pattern studies give us the feedback on over or under prescription of drugs, on rational use of drugs and its cost-benefit analysis.

\section{ACKNOWLEDGEMENTS}

Authors would like to thank and extend their gratitude to the postgraduate students and resident doctors of Department of Pharmacology and Department of ENT, Pt. J.N.M. Medical College, Raipur, India.

\section{Funding: No funding sources}

Conflict of interest: None declared

Ethical approval: The study was approved by the Institutional Ethics Committee

\section{REFERENCES}

1. WHO expert committee. The selection of essential drugs, technical report series no. 615, Geneva: WHO 1977.

2. Bergman U. The history of drug utilization research group in Europe. Pharmacoepidemiol drug saf. 2005;15(2):95-8.

3. Pradhan SC, Shewade DG, Shashindran CH, Bapna JS. Drug utilization studies. National Med J India. $1988 ; 1 ; 185-9$.

4. World Health Organisation. The rational use of drug: report of the conference of experts, Nairobi; November 1985:25-29.
5. Njoroge GN, Bussman RW. Traditional management of ear, nose and throat (ENT) diseases in central Kenya. J Ethnobiol Ethnomed. 2006;2:54.

6. WHO; The global Burden of Disease; 2004- Page10Fig 4-Distribution of deaths by leading cause groups, males and females, world; 2004. Available at: www.who.int/healthinfo/global_burden_diseases/GB D_report_2004update_full.pdf

7. Krishnaswamy K, Kumar BD, Radhaiah G. A drug survey- percept and practices. Eur J Clin Pharmacol. 1985;29(3):363-70.

8. WHO. How to investigate drug use in health facilities: selected drug use indicators. WHO/DAP/93.1. Geneva: WHO;1993.

9. Pradhan S, Jauhari AC. A study of antibiotics used in adult respiratory disorders in Kathmandu and Bhaktpur. Nepal Med Coll J. 2007;9:120-4.

10. Sridevi SA, Janagan A, Rathnasamy P, Rajarajeswari R. Drug utilization study in the otorhinolaryngology department in a tertiary care hospital. Int J Basic Clin Pharmacol. 2013;2(3):306-10.

11. Padwal SL, Kulkarni MD, Deshmukh VS, Patil JR, Jadhav AD. Drug use pattern in the ear, nose, throat outpatient department of a rural tertiary-care teaching hospital. Natl J Physiol Pharmacol. 2015;5:212-6.

12. Bhat GMN, Holla R, Kamath PSD. A study of prescription pattern in the drug therapy of ear, nose and throat infections at a tertiary care hospital in Mangalore. Int J Basic Clin Pharmacol. 2015;4:68690.

13. Atanasova I, Terziivanov D. Investigations on antibiotics in a hospital for a one year period. Int J Clin Pharmacol Ther. 1995;33:32-3.

14. Till B, Williams L, Oliver SP, Pollans PI. A survey of inpatient antibiotic use in a teaching hospital. S Afr Med J. 1991;8:7-10.

15. Sumalatha R, Nagabushan H, Prasad HM. Drug utilization study in otorhinolaryngology outpatient department in a tertiary care teaching hospital. Int $\mathbf{J}$ Basic Clin Pharmacol. 2017;6:572-6.

16. Anandhasayanam A, Kannan S, Md Sajir, Zachariah N. Drug Prescription Pattern Obversation at an ENT OPD Department in a Tertiary Care Hospital at Malappuram District of Kerala. Int J Pharm Sci Res. 2016;7(10):4157-63.

17. Khan FA, Nizamuddin S, Salman MT. Patterns of prescription of antimicrobial agents in the department of otorhinolaryngology in a tertiary care teaching hospital. Int Res $\mathbf{J}$ Pharmacy and Pharmacol. 2011:1(5)79-85.

18. Suman RK, Kumar R, Garje YA, Wagh AR, Satpathy A, Ray IM. Drug usage patterns in Ent Out Patients Department of Teaching Hospital. Int J Sci Res. 2014:3(7):341-3.

Cite this article as: Joshi U, Banjara H, Hishikar R, Chandrakar R. Prescription pattern of drugs in ENT outpatient department of tertiary care teaching hospital. Int J Basic Clin Pharmacol 2018;7:1688-92. 